\title{
The Intersection of HPV Epidemiology, Genomics and Mechanistic Studies of HPV-Mediated Carcinogenesis
}

\author{
Lisa Mirabello ${ }^{1, *}$, Megan A. Clarke ${ }^{1}$, Chase W. Nelson ${ }^{1,2}$, Michael Dean ${ }^{1}$, \\ Nicolas Wentzensen ${ }^{1}$, Meredith Yeager ${ }^{1,3}$, Michael Cullen ${ }^{1,3}$, Joseph F. Boland ${ }^{1,3}$, \\ NCI HPV Workshop ${ }^{4,+}$, Mark Schiffman ${ }^{1}$ and Robert D. Burk ${ }^{5, *}$ (i)
}

1 Division of Cancer Epidemiology and Genetics (DCEG), National Cancer Institute, National Institutes of Health, Rockville, MD 20850, USA; megan.clarke@nih.gov (M.A.C.); cnelson@amnh.org (C.W.N.); deanm@mail.nih.gov (M.D.); wentzenn@mail.nih.gov (N.W.); yeagerm@mail.nih.gov (M.Y.); michael.cullen@nih.gov (M.C.); bolandj2@mail.nih.gov (J.F.B.); schiffmm@mail.nih.gov (M.S.)

2 Sackler Institute for Comparative Genomics, American Museum of Natural History, New York, NY 10024, USA

3 Cancer Genomics Research Laboratory, Leidos Biomedical Research, Inc., Frederick, MD 21701, USA

4 NCI HPV Workshop, DCEG, Rockville, MD 20850, USA; sara.bass2@nih.gov

5 Departments of Pediatrics, Microbiology and Immunology, Epidemiology and Population Health, and Obstetrics \& Gynecology and Women's Health, Albert Einstein College of Medicine, Bronx, NY 10461, USA

* Correspondence: mirabellol@mail.nih.gov (L.M.); robert.burk@einstein.yu.edu (R.D.B.)

+ Attendees (not already listed as co-authors, alphabetical order): Laia Alemany, Lawrence Banks, Sara Bass, Chris Buck, Laurie Burdett, Anil Chaturvedi, Gary Clifford, Daniel DiMaio, John Doorbar, Allan Hildesheim, Lou Laimins, Paul Lambert, Hong Lou, Alison McBride, Karl Munger, Miguel Angel Pavón Ribas, Ligia Pinto, John Schiller, Richard Schlegel, Stefan Schwartz, Mia Steinberg, Sarah Wagner, Yanzi Xiao, Qi Yang, Kai Yu, Bin Zhu (Supplementary Materials Table S1 lists attendee affiliations).

Received: 9 December 2017; Accepted: 12 February 2018; Published: 13 February 2018

\begin{abstract}
Of the $\sim 60$ human papillomavirus (HPV) genotypes that infect the cervicovaginal epithelium, only 12-13 "high-risk" types are well-established as causing cervical cancer, with HPV16 accounting for over half of all cases worldwide. While HPV16 is the most important carcinogenic type, variants of HPV16 can differ in their carcinogenicity by 10-fold or more in epidemiologic studies. Strong genotype-phenotype associations embedded in the small 8-kb HPV16 genome motivate molecular studies to understand the underlying molecular mechanisms. Understanding the mechanisms of HPV genomic findings is complicated by the linkage of HPV genome variants. A panel of experts in various disciplines gathered on 21 November 2016 to discuss the interdisciplinary science of HPV oncogenesis. Here, we summarize the discussion of the complexity of the viral-host interaction and highlight important next steps for selected applied basic laboratory studies guided by epidemiological genomic findings.
\end{abstract}

Keywords: HPV carcinogenesis; HPV epidemiology; HPV genomics; viral-host interactions; HPV16

\section{Background}

High-risk human papillomaviruses (HR-HPVs) cause a heavy burden of cancer with more than 600,000 cancers attributed to HR-HPVs worldwide in 2008 [1-3]. Of these patients, 236,000 deaths are estimated to be caused by cervical cancer alone each year [4]. Yet, the genetic basis of HPV oncogenicity, firmly established for one clade of the genus Alphapapillomavirus [5], has not been solved. This research question is now tractable, given the strong genotype-phenotype associations, the availability of fundamental molecular biological knowledge regarding the small HPV genome, and recent advances in high-throughput sequencing of HPV genomes. 
Papillomaviruses (PVs) are circular, double-stranded DNA viruses that are believed to have co-diverged with animal and human host populations for millions of years, and are ubiquitous throughout the world [6-9]. HPV genomes are approximately 8000 base pairs in length and contain eight to nine open reading frames (ORFs) that encode highly conserved core proteins involved in viral genome replication (E1 and E2/E4) and assembly (L1 and L2), as well as accessory proteins (E5, E6, and E7). While E1 and E2 are involved in HPV replication and in regulating viral transcription, the primary oncogenes, E6 and E7, are thought to be largely responsible for niche adaptation, viral amplification, and inadvertently driving carcinogenesis [10]. Niche adaptation refers to the virus adapting to a specific anatomic/cellular region. All HPV genomes contain E7, and a few lack E6 and E5 [11]. The upstream regulatory region (URR) is a non-coding region containing cis-responsive elements that regulate replication and transcription of viral proteins [12].

HPV types are classified based on pairwise nucleotide sequence identity within the highly conserved L1 gene, and distinct types (e.g., HPV16 vs. HPV31) are defined by differences of at least $10 \%$ at the nucleotide level [13]. An HPV species group (e.g., Alphapapillomaviruses-9) comprises HPV types sharing $\geq 70 \%$ of their L1 sequences [13]. To date, more than $200 \mathrm{HPV}$ types have been identified and characterized [13]. Some HPV types within the alpha-HPVs infect mucosal epithelia and are associated with a variety of outcomes, ranging from benign asymptomatic infections to genital warts and cervical cancer. Of the $\sim 60$ alpha-HPV types, 13 from a single clade (i.e., branch of the phylogenetic tree) have been classified as definitely or probably carcinogenic (high-risk) and account for $>95 \%$ of all cervical cancers worldwide. These include HPV16, HPV31, HPV33, HPV35, HPV52 and HPV58 (Alphapapillomaviruses-9 species group); HPV18, HPV39, HPV45, HPV59, and HPV68 (Alphapapillomaviruses-7 species group); HPV51 (Alphapapillomaviruses-5 species group); and HPV56 (Alphapapillomaviruses-6 species group) [14]. On a finer scale, within each of these HPV types there are variant lineages and sublineages with intratypic genome sequence differences of $1.0-10 \%$ and $0.5-1.0 \%$, respectively [15].

HPV16 is by far the most carcinogenic HPV type, associated with approximately $50 \%$ of all cervical cancers, the majority of other HPV-related anogenital cancers, and more than $80 \%$ of HPV-positive head and neck cancers [16-20]. HPV16 variant lineages have been extensively studied, with four major variant lineages and up to 16 sublineages identified to date (Figure 1), including: sublineages A1-3 (traditionally classified as European), A4 (Asian), B1-4 (African-1), C1-4 (African-2), D1 (North American), D2 and D3 (Asian-American), and D4 [15,21]. Several studies have demonstrated that HPV16 variant lineages and sublineages confer differential risks of persistence, and progression to cervical precancer and cancer [21-33] (reviewed in Burk et al. [15]). The epidemiologically-defined co-factors, smoking and use of hormonal contraceptives, do not modify HPV16 variant lineage risk substantially [28], however, HPV16 lineages have not been evaluated considering host genetic factors and this could modify risk slightly. Some authors further showed that specific HPV16 lineages are associated with glandular versus squamous histology [21,26,32,34-36]. 


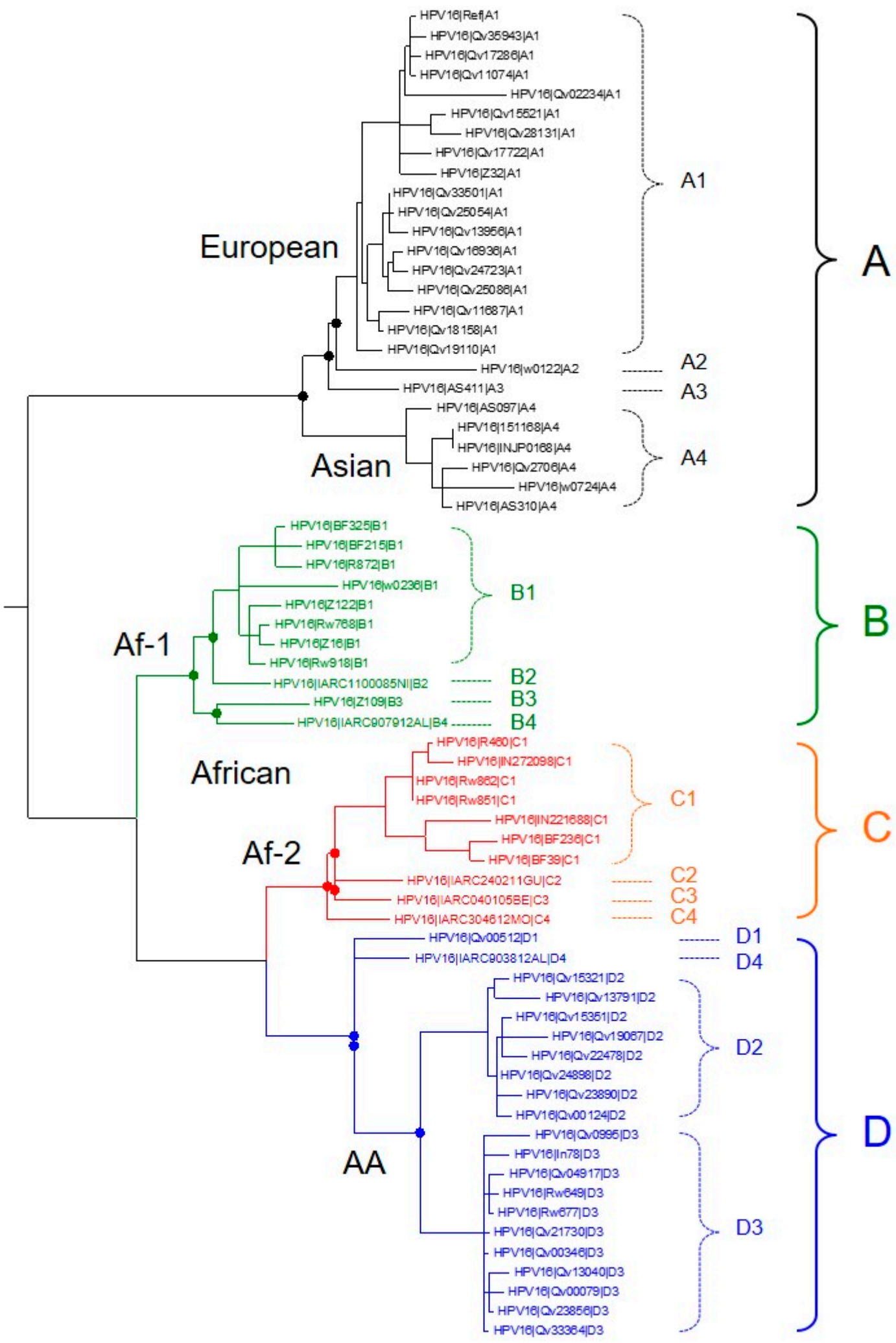

Figure 1. Phylogenetic tree illustrating human papillomavirus 16 (HPV16) lineages (A-D) and sublineage (A1-4, B1-4, C1-4, D1-4) relationships. Colors indicate main lineage branches. A maximum likelihood tree is shown inferred from 66 HPV16 whole-genome sequences, modified from Burk et al., 2013 [15], including additional reference sequence data from Mirabello et al. 2016 [21], 2017 [37]. Af-1, African-1; Af-2, African-2; AA, Asian-American. 
Recent advances in high-throughput next-generation sequencing [38] have enabled the large-scale study of HPV genome variability and led to new discoveries in HPV genomic research. These findings based on empirical population-based studies provide opportunities for further investigation at the intersection of molecular biology and epidemiology that could enhance our molecular understanding of HPV-related carcinogenesis. In recognition of this exciting and unique opportunity, the National Cancer Institute's (NCI) Division of Cancer Epidemiology and Genetics (DCEG) sponsored a workshop entitled "Mechanistic Understanding of Cervical Carcinogenesis" on 21 November 2016. Planning and organization of the workshop was led by Lisa Mirabello and Robert D. Burk of the NCI-DCEG HPV Genomics Group. The primary goal of this workshop was to promote interdisciplinary discussions on the potential mechanisms underlying differences in carcinogenicity at the HPV type, lineage, and nucleotide levels and the potential next steps. The workshop brought together an expert panel spanning biochemistry, molecular biology, evolution, pathology, epidemiology, bioinformatics and statistics (Supplementary Materials Table S1). Some of the members of the NCI-DCEG HPV Genomics Group (Robert D. Burk, Mark Schiffman, Nicolas Wentzensen, and Lisa Mirabello) briefly presented the latest HPV epidemiologic and genomic data, and the majority of the workshop was focused on panel discussions addressing specific questions about the molecular mechanisms of HPV carcinogenesis defined by differences in HPV genomes that have remained unresolved (Table 1). This report summarizes the main highlights from this Workshop, with the goal of stimulating further research to understand the specific mechanisms underlying HPV carcinogenesis.

Table 1. Topics and specific questions addressed at the National Cancer Institute (NCI) HPV Workshop.

\begin{tabular}{|c|c|}
\hline Topic Area & Questions \\
\hline \multirow{4}{*}{$\begin{array}{l}\text { HPV studies at the species and/or type } \\
\text { level and risk of cancer }\end{array}$} & $\begin{array}{l}\text { What features of the biology and/or biochemistry of HPV16 make it so } \\
\text { uniquely carcinogenic? }\end{array}$ \\
\hline & $\begin{array}{l}\text { What features of HPV16 biology, or interaction with the host cells, enable it } \\
\text { to have a wider tissue tropism and disease association? }\end{array}$ \\
\hline & What are the experimental approaches to investigate this? \\
\hline & $\begin{array}{l}\text { - This should include comparisons of closely related HPV types } \\
\text { (i.e., HPV16, 31, and 35) with large differences in carcinogenesis } \\
\text { Comparison of appropriate type(s) to HPV16/18 biology/biochemistry } \\
\text { (HPV6/11 are probably not a good choice because they are } \\
\text { evolutionarily distant) }\end{array}$ \\
\hline \multirow{4}{*}{$\begin{array}{l}\text { Studies of HPV variant lineages within } \\
\text { a type to elucidate differences and risk } \\
\text { of cancer }\end{array}$} & $\begin{array}{l}\text { Are there functional differences between HPV16 A1 vs. D sublineage viruses } \\
\text { that could help explain their pathological differences in cancer risk? }\end{array}$ \\
\hline & $\begin{array}{l}\text { - How do we mechanistically explain the genetic variants associated } \\
\text { with glandular lesions for the HPV16 A4, D2, D3 sublineages compared } \\
\text { to A1 and A2? }\end{array}$ \\
\hline & $\begin{array}{l}\text { Why are specific HPV16 sublineages (i.e., A4, D2, D3), and HPV18 and } \\
\text { HPV45 prone to adenocarcinoma? }\end{array}$ \\
\hline & $\begin{array}{l}\text { What are the next steps after the SNP/gene-based epidemiological approach } \\
\text { using case-control datasets? What cell based and/or biochemical } \\
\text { experiments could be used to identify the mechanisms of different } \\
\text { genetic associations? }\end{array}$ \\
\hline \multirow{5}{*}{$\begin{array}{l}\text { Synthesizing current knowledge and } \\
\text { moving forward in the era of NGS, } \\
\text { systems biology and large data sets }\end{array}$} & $\begin{array}{l}\text { How do we define the characteristics of HPV fitness? } \\
\text { How do we annotate HPV genomes to be able to capture common functional } \\
\text { motifs with disparate genomes in large datasets? (e.g., it's hard to align a } \\
\text { large number of genome sequences of HPV16 with HPV31, HPV52, etc) }\end{array}$ \\
\hline & - How do we go beyond the annotations in NCBI and PaVE? \\
\hline & $\begin{array}{l}\text { How do we incorporate information on viral suppression/invisibility to the } \\
\text { host immune system? }\end{array}$ \\
\hline & $\begin{array}{l}\text { Where does epigenetics of the viral genome fit into the discussion of } \\
\text { dissecting viral genome differences? }\end{array}$ \\
\hline & How to best approach viral-host interactions? \\
\hline
\end{tabular}




\section{Recent Discoveries in HPV Genomics}

Through an international collaborative effort, the NCI HPV Genomics Project has sequenced many thousands of HPV genomes from well-characterized populations. With an initial focus on HPV16, recent data have confirmed and expanded earlier reports relating precancer/cancer risk to particular HPV16 lineages and uncovered several remarkably strong associations between HPV16 genetic variation and cervical carcinogenicity, as well as providing new insights into HPV diversity in the population. We have applied lineage-based and agnostic, gene and single nucleotide polymorphism (SNP)-based approaches to studying HPV genetic variation [21,38]. At the lineage-level, HPV16 sublineages confer differing risks of precancer and cancer, and most strikingly, differing risks of glandular lesions [21,26,32,34-36] which are of rising public health importance-they are more difficult to detect with cytology, have a poorer prognosis than squamous cell carcinoma (SCC), and their proportion among all cancers have been shown to be increasing in many developed regions [39-44]. The HPV16 sublineages, A4, D2, and D3, have significantly increased risks of adenocarcinoma in situ (AIS) and adenocarcinoma (ADC) compared to the most common A1/A2 sublineages; D3 and D2 have the strongest risks of ADC with relative risks of 59 and 137, respectively [21]. This indicates that only a small number of genetic differences (e.g., D and A HPV16 sublineages differ by $<2.0 \%$ of $7906 \mathrm{nt}$ ) lead to large differences in risk of ADC.

Next-generation sequencing (NGS) HPV genome data with deep sequence coverage allows the sensitive identification of within HPV16 variant lineage co-infections. Using these data, within type co-infections are suspected in women with multiple "heterozygous" allele calls (HPV is a monoploid genome). The co-infections can be confirmed by the identification and visualization of multiple lineage-specific sequence variants occurring in shared sequence reads, representing two separate HPV16 variant lineage isolates. In the case of multiple lineages present in a specimen, a predominant lineage can usually be assigned based on presence in at least $60 \%$ of the sequence reads, and nucleotide variants only included from the predominant lineage; and, if a predominant lineage cannot be assigned ( $50 / 50$ of each lineage), that sample excluded (for more detail, see Cullen et al., [38]).

To address whether even finer genetic variation (i.e., SNPs) is associated with HPV16 carcinogenicity, we evaluated non-lineage-specific SNPs and the distribution of rare variants occurring within HPV16 lineages in a collection of 5,570 HPV16-infected case-control samples [37]. Thousands of unique HPV16 viral isolates were identified among women, suggesting that each may represent a distinct viral genome sequence possibly differing in carcinogenic potential. The controls had higher levels of rare sequence variants (particularly nonsynonymous and nonsense variants, i.e., amino acid changing) compared with cases across the genome and in specific regions. Interestingly, focusing on non-silent variation, $E 7$ was more variable in the controls compared to the cases, and we confirmed that E7 showed extremely low variability in $~ 1700$ cervical cancers from around the world. The E7 gene was significantly less variable than all other gene regions in the cancers, including E6. This highlights that genetic conservation of $E 7$ (but not E6) is critical for HPV16 carcinogenesis. These rare nucleotide variants in $E 7$ frequently occurred in DNA motifs that are associated with the antiviral activity of human APOBEC3 (apolipoprotein B mRNA-editing, enzyme-catalytic polypeptide-like 3) family of cytidine deaminases. Interestingly, the majority of cervical cancer cases have been shown to be enriched for somatic APOBEC mutation signatures, suggesting that APOBEC antiviral activity is also a major source of somatic mutations in cervical cancers $[45,46]$.

As discussed by the panel, these findings suggest that genetic variation within specific regions of the genome may differentially allow the virus to be cleared by the host; alternatively, the phenotype of cancer may require a fixed set of nucleotide variants at the viral genome level.

\section{Summary/Next Steps: Molecular Mechanisms Underlying HPV Carcinogenesis}

The Workshop agenda outlined many key questions related to three broad topic areas for discussion (Table 1). The first two sessions addressed molecular mechanisms underlying HPV carcinogenesis at the type and variant lineage/sublineage level, respectively. Each attendee was 
asked to contribute to these discussions by providing their unique perspective based on their expertise, for example, in basic science, epidemiology and/or computational biology. The following sections present an overview of the major themes that emerged.

\subsection{Viral Molecules and Their Interactions with Host Cellular Machinery}

The HPV life cycle is tightly linked to the differentiation state of infected epithelial cells. HPV infects basal keratinocytes that are exposed as the result of micro-abrasions in the epithelial surface [47,48]. Viral genome replication occurs at low levels in the basal layer and, as infected cells undergo terminal differentiation in the upper layers of the epithelium, E6 and E7 drive genome amplification by promoting cell-cycle re-entry and proliferation of HPV-infected cells $[49,50]$. Functional differences in E6 and E7 are thought to determine differences in carcinogenicity between high-risk and low-risk HPV types. Further, differences in the regulation of host protein interactions have been observed across high-risk types, which may contribute to known differences in carcinogenicity [51,52]. In addition, most viral proteins are expressed from spliced RNA molecules that have a complex regulation. Correlated changes across the viral genome could account for large changes in infection outcome (clearance, persistence and progression), as described in epidemiologic studies.

\subsection{Tissue Tropism and Site of Infection}

HPV infections can occur within specific sites of transitional epithelial cells (e.g., the squamocolumnar junction) with complex patterns of regulation that may render them more prone to viral transformation $[48,53,54]$. At glandular sites such as the endocervix and tonsils, the diagnosis and/or presence of precursor lesions compared to invasive cancers is much lower than the diagnosis of cervical squamous intraepithelial lesions to squamous cell cancers [55]. Whether this is due to the position of the lesions and impact on screening efficacy, morphologic features of the precursors, or is related to actual differences in HPV natural history and oncogenesis is not fully understood [56]. Since E6 and E7 may induce a stem cell-like state, the type of cell that becomes infected may contribute to disease outcome. More research is needed to understand whether patterns of viral gene expression and protein function are site-specific, and how they vary across different high-risk HPV types. Specific observations that need explanation include the relatively high prevalence of precancers (i.e., CIN3) that do not translate into similar rates of cancer, suggesting that precancer is a distinct endpoint that does not serve as a perfect surrogate for cancer risk. For example, the ratio of HPV31 to HPV16 is much higher for CIN3 than for cancer, suggesting that a higher proportion of CIN3s caused by HPV31 do not lead to cancer.

\subsection{Regulation of HPV Transcription}

High-risk HPV types have evolved regulatory strategies to tightly control viral gene expression during productive and quiescent infections. Because of its critical role in regulating gene expression at different stages of the HPV life cycle, mRNA splicing efficiency may contribute to carcinogenic potential [57]. Recent findings from The Cancer Genome Atlas (TCGA) suggest that in HPV16 there is a lower ratio of spliced E6 transcripts (coding for E7) to unspliced transcripts (coding for E6) compared with HPV18 [45]. Thus providing some of the evidence that mechanisms of carcinogenesis differ between these Alphapapillomaviruses-9 and Alphapapillomaviruses-7 genomes and probably relates to their genetic differences. Efficiency of splicing may also differ [57,58], since HPV mRNA splicing and polyadenylation are regulated by cis-acting HPV RNA elements and cellular RNA-binding proteins. Synonymous, nonsynonymous and non-coding sequence differences in binding motifs or RNA structures may induce subtle changes in splicing and/or polyadenylation efficiencies that could have significant effects on viral gene expression and thus, carcinogenicity. However, to date, over 1000 host RNA binding proteins have been identified [59] and their ability to recognize and bind to multiple sequence motifs makes it particularly challenging to predict differences in splicing and/or polyadenylation across types or lineages by sequencing alone. In addition to primary sequence 
variation, secondary structures may influence the efficiency of RNA binding and can be difficult to predict. One approach discussed at the meeting involves transfecting various HPV16 isolates differing in oncogenicity and measuring viral RNA molecules through RNA sequencing approaches (RNA-Seq or whole transcriptome sequencing).

In vitro studies have recently shown that HPV16 and related types express a fusion protein encoded by subregions of the E1 and E2 ORFs (termed E8^E2), which limits viral transcription and replication through the virus life cycle in undifferentiated keratinocytes [60]. This may play an important role in keeping the expression of early viral proteins at low levels so as to evade immune detection. Whether this protein occurs in natural infections remains untested, but it is an additional region that should be evaluated for any genome variation that might influence the viral life cycle and pathogenesis.

\subsection{HPV Integration into Host Genomes}

Integration of HPV DNA into the host genome occurs in the majority of cervical cancers, but not all $[61,62]$. Mechanisms by which HPV integrates into the host cell genome and promotes carcinogenesis are not well understood. Sites of integration tend to occur in regions of genomic instability [63-65], and have also been reported to occur in short regions of HPV and host genome sequence homology (i.e., "micro-homologies") [66-68], suggesting a potential role for DNA repair processes in integrating the HPV and host cell genomes based on nucleotide sequence similarities [69]. The prevalence of HPV integration in cervical cancers has been shown to vary by type, with lower frequencies observed for HPV types 31 and 33, compared with HPV types 16, 18, and 45 [61,69]. As a finer distinction, not all HPV16-associated cancers have integrated HPV DNA, whereas HPV18 integration is present in almost all HPV18-associated cancers. Viral-cellular fusion transcripts have been detected in all HPV18-positive cancers, some occurring in previously identified hotspots, such as 8q24 [45]. Interestingly, integration events associated with HPV18 appear to be more common at 8q24.21 near the MYC oncogene compared with HPV16-associated cancers [69,70]. At the HPV variant level, a recent study characterizing integration events by the HPV16 D and A variant lineages suggested differences in variant-specific integration potential, potentially mediated by E6 [71]. More studies are needed to confirm these findings and determine if and how viral genetic variation might relate to integration.

\subsection{Viral-Host Interactions}

In response to infection with HPV, humans can mount an adaptive immune response including the development of specific antibodies to the virion L1 coat protein. Antibody and/or human cytotoxic T-lymphocyte (CTL) epitopes have been predicted within the peptides encoded by all HPV16 ORFs: $100 \%$ of $E 5, E 6$, and $E 7$ residues; $65-83 \%$ of $E 2, E 4$, and $L 1$ residues; and only $7 \%$ of $E 1$ residues (Immune Epitope Database). E6 and E2 epitopes appear to be the most important for a CTL response [72].

Alternative approaches for identifying potentially important HPV epitopes are based on evolutionary methods to identify positive selection that might indicate a pressure for immune escape, and these have mainly detected codons in the E5, E6, L1, and L2 ORFs [11,73]. Future research in this area will take advantage of increasingly available sequence data to detect regions undergoing positive selection within sublineages, helping to elucidate sublineage- and case/control-specific immune responses.

Both genetic and environmental host factors play key roles in determining viral oncogenicity. Epidemiologically defined co-factors, such as smoking and use of hormonal contraceptives, also play a role-for example, smoking has been associated with an approximate two-fold increased risk of precancer and cancer [74]. One goal of future research should be to link both host factors/genetics and viral genetics to infection outcomes. The host human leukocyte antigen (HLA) allele repertoire in particular, which is crucial for cell-mediated immune responses, may be a critical factor in determining which HPV variants will clear, and which will persist and potentially evade the immune system. 
In fact, these host immune alleles show signals for an inherited risk of cervix precancer/cancer [75-77]. Furthermore, specific HLA class I alleles have been associated with the oncogenicity of specific HPV16 variants [78,79], which highlights the importance of the HLA type combined with the HPV16 variants for immune surveillance in cervical carcinogenesis. The development of cancer may include such steps as an HPV variant infecting a host, who has an insufficient HLA repertoire for clearing that particular variant.

\section{Synthesizing Current Knowledge and Moving Forward in the Era of NGS, Systems Biology, and Big Data}

The final session covered a range of topics related to characterizing and defining HPV fitness, annotation of HPV genomes, and host-viral interactions. These topics have important implications for HPV genomics research and could serve as a model for other genetic systems.

\subsection{Defining HPV "Fitness"}

Evolutionary fitness in biology is usually defined as reproductive success. The definition of how to define viral fitness in general, and HPV fitness in particular, remains unresolved and was not agreed upon by the workshop panel. An increase in viral replicative success may have conflicting proximal and ultimate outcomes for the host. For example, a particular viral genotype may replicate to high viral load in a particular cell, but the outcome may be to increase the likelihood of an immune response, thereby drastically decreasing the actual fitness of the virus. Surprisingly, much of the feedback from the panel was that a consensus definition for fitness might not be useful for describing carcinogenic features of different HPV types and variants. The intellectual divide resided in whether viral evolution, niche adaptation, and fitness represent the key drivers of carcinogenesis, although carcinogenesis does not support viral replication. Some attendees suggested a more direct paradigm using viral outcomes, such as causing cancer or not, as the "viral" phenotype (Table 2). Others suggested defining fitness as viral prevalence in the infected population, i.e., the outcome of incidence and persistence. In addition, the steps to cancer can be considered either as independent outcomes (e.g., persistence, precancer), or as a sequential set of steps that could be studied using functional assays.

Table 2. Distinct steps in the pathway from HPV infection to carcinogenesis.

\begin{tabular}{ll}
\hline \multicolumn{1}{c}{ Functional Step } & \multicolumn{1}{c}{ Relevant Features } \\
\hline 1. Infection & $\begin{array}{l}\text { Cell receptor(s) for entry } \\
\text { Tissue tropism }\end{array}$ \\
\hline \multirow{3}{*}{ 2. Persistence } & $\begin{array}{l}\text { Continued productive infection } \\
\text { Persistence without productive infection } \\
\text { Cellular immunity } \\
\text { Latency } \\
\text { Early, inapparent transformation }\end{array}$ \\
\hline \multirow{3}{*}{ Transformation } & $\begin{array}{l}\text { Increased E6/E7 expression } \\
\text { Chromosomal instability } \\
\text { Somatic mutations } \\
\text { Viral integration }\end{array}$ \\
\hline \multirow{3}{*}{ Invasion } & $\begin{array}{l}\text { Increasing somatic mutations } \\
\text { Integration, disruption, and partial loss of viral genome } \\
\text { Epithelial-stromal interactions }\end{array}$ \\
\hline
\end{tabular}

Given that the most prevalent anogenital HPV type (HPV16) is also the most carcinogenic, future research should consider the relationship between viral prevalence and oncogenicity. It appears that viral traits that improve reproductive success also tend to initiate processes that predispose host cells to cancer. In either case, the ability to induce cancer is neither necessarily, nor inextricably, linked to HPV's ability to successfully propagate in populations, such that oncogenicity may be considered an 
unfortunate byproduct that is not itself under selection. Adaptation to a specific cellular environment may define features of the HPV genome that induce cancer as "collateral damage" rather than a selective trait, since cancer does not support the production of infectious virus.

\subsection{HPV Genome Annotation and Other New Emerging Data Concepts}

The importance of genome annotation is critical for evaluating the impact of sequence variations across viral variants and between viral types. In fact, since the variation between viral types is so large (approximately 30\%), unequivocal alignment and position assignments are not currently feasible. Therefore, annotation of functions could serve as a common database to connect different features of disparate genomes. The way forward was not defined, but a bioinformatic approach is a promising area that could build upon work done on the annotation of various mammalian genomes that face similar challenges.

\section{Conclusions}

The field of HPV genomics is undergoing a major paradigm shift from thinking of an HPV type infection as an evolutionarily static entity to thinking of thousands of unique viral genomes with differences in carcinogenic potential. Findings from recent large epidemiologic studies defining the association of HPV variant lineages/sublineages/SNPs with cervical cancer risk have led to new discoveries that call for HPV natural history and carcinogenesis to be re-visited. These findings also merit additional experimental studies using tools developed in the "omics" era. These novel discoveries underscore the importance of designing relevant comparisons to help sort out the differences in viral genetic features of carcinogenesis at the biochemical and mechanistic level. For example, across HPV genotypes, a large number of nucleotide differences may reveal more broad associations between HPV type and processes such as viral-host interactions, tissue tropism at the cellular level, splicing, and protein translation. In contrast, variant lineage/sublineage studies within a particular HPV type will allow for the identification of individual variants, or small groups of variant sites (haplotypes), related to differences in carcinogenicity. Integrating epidemiologic findings with functional studies may transform our basic understanding of HPV-associated carcinogenesis and may eventually elucidate the genetic basis defining what makes some HPVs, especially HPV16, such powerful carcinogens.

HPV carcinogenesis is a multifactorial complex process that involves a confluence of viral and host factors. However, compared with the complexities associated with studying the human genome, the genetic basis of HPV carcinogenicity in an $8000 \mathrm{bp}$ genome is a more tractable problem that deserves immediate attention.

Supplementary Materials: The following are available online at www.mdpi.com/1999-4915/10/2/80/s1, Table S1: Full list of workshop attendees.

Acknowledgments: We thank Zigui Chen (The Chinese University of Hong Kong) for help with the HPV16 phylogenetic tree. This study was funded by the intramural research program of the Division of Cancer Epidemiology and Genetics, National Cancer Institute, National Institutes of Health. The content of this publication does not necessarily reflect the views or policies of the Department of Health and Human Services, nor does mention of trade names, commercial products, or organizations imply endorsement by the U.S. Government. This work was supported in part by the National Cancer Institute (CA78527) and the Einstein Cancer Research Center (P30CA013330) from the National Cancer Institute (to Robert D. Burk). Chase W. Nelson was supported by a Gerstner Scholars Fellowship from the Gerstner Family Foundation at the American Museum of Natural History.

Author Contributions: Lisa Mirabello and Robert D. Burk organized and led the workshop; all authors and attendees contributed to the workshop; Lisa Mirabello, Robert D. Burk, Megan A. Clarke and Chase W. Nelson drafted the manuscript; all authors participated in the editing of the manuscript.

Conflicts of Interest: The authors declare no conflict of interest. 


\section{References}

1. Forman, D.; de Martel, C.; Lacey, C.J.; Soerjomataram, I.; Lortet-Tieulent, J.; Bruni, L.; Vignat, J.; Ferlay, J.; Bray, F.; Plummer, M.; et al. Global Burden of Human Papillomavirus and Related Diseases. Vaccine 2012, 30 (Suppl. 5), F12-F23. [CrossRef] [PubMed]

2. De Martel, C.; Ferlay, J.; Franceschi, S.; Vignat, J.; Bray, F.; Forman, D.; Plummer, M. Global burden of cancers attributable to infections in 2008: A review and synthetic analysis. Lancet Oncol. 2012, 13, 607-615. [CrossRef]

3. De Martel, C.; Plummer, M.; Vignat, J.; Franceschi, S. Worldwide burden of cancer attributable to HPV by site, country and HPV type. Int. J. Cancer 2017, 141, 664-670. [CrossRef] [PubMed]

4. Global Burden of Disease Cancer Collaboration. The global burden of cancer 2013. JAMA Oncol. 2015, 1, 505-527.

5. Schiffman, M.; Herrero, R.; Desalle, R.; Hildesheim, A.; Wacholder, S.; Rodriguez, A.C.; Bratti, M.C.; Sherman, M.E.; Morales, J.; Guillen, D.; et al. The carcinogenicity of human papillomavirus types reflects viral evolution. Virology 2005, 337, 76-84. [CrossRef] [PubMed]

6. Chan, S.Y.; Bernard, H.U.; Ong, C.K.; Chan, S.P.; Hofmann, B.; Delius, H. Phylogenetic analysis of 48 papillomavirus types and 28 subtypes and variants: A showcase for the molecular evolution of DNA viruses. J. Virol. 1992, 66, 5714-5725. [PubMed]

7. Yamada, T.; Manos, M.M.; Peto, J.; Greer, C.E.; Munoz, N.; Bosch, F.X.; Wheeler, C.M. Human papillomavirus type 16 sequence variation in cervical cancers: A worldwide perspective. J. Virol. 1997, 71, 2463-2472. [PubMed]

8. Pimenoff, V.N.; de Oliveira, C.M.; Bravo, I.G. Transmission between Archaic and Modern Human Ancestors during the Evolution of the Oncogenic Human Papillomavirus 16. Mol. Biol. Evol. 2017, 34, 4-19. [CrossRef] [PubMed]

9. Chen, Z.; van Doorslaer, K.; DeSalle, R.; Wood, C.E.; Kaplan, J.R.; Wagner, J.D.; Burk, R.D. Genomic diversity and interspecies host infection of alpha12 Macaca fascicularis papillomaviruses (MfPVs). Virology 2009, 393, 304-310. [CrossRef] [PubMed]

10. Schiffman, M.; Doorbar, J.; Wentzensen, N.; de Sanjosé, S.; Fakhry, C.; Monk, B.J.; Stanley, M.A.; Franceschi, S. Carcinogenic human papillomavirus infection. Nat. Rev. Dis. Primers 2016, 2, 16086. [CrossRef] [PubMed]

11. Van Doorslaer, K. Evolution of the papillomaviridae. Virology 2013, 445, 11-20. [CrossRef] [PubMed]

12. Bernard, H.U. Regulatory elements in the viral genome. Virology 2013, 445, 197-204. [CrossRef] [PubMed]

13. Bernard, H.U.; Burk, R.D.; Chen, Z.; van Doorslaer, K.; zur Hausen, H.; de Villiers, E.M. Classification of papillomaviruses (PVs) based on 189 PV types and proposal of taxonomic amendments. Virology 2010, 401, 70-79. [CrossRef] [PubMed]

14. Bouvard, V.; Baan, R.; Straif, K.; Grosse, Y.; Secretan, B.; El Ghissassi, F.; Benbrahim-Tallaa, L.; Guha, N.; Freeman, C.; Galichet, L.; et al. A review of human carcinogens-Part B: Biological agents. Lancet Oncol. 2009, 10, 321-322. [CrossRef]

15. Burk, R.D.; Harari, A.; Chen, Z. Human papillomavirus genome variants. Virology 2013, 445, $232-243$. [CrossRef] [PubMed]

16. Guan, P.; Howell-Jones, R.; Li, N.; Bruni, L.; de Sanjosé, S.; Franceschi, S.; Clifford, G.M. Human papillomavirus types in 115,789 HPV-positive women: A meta-analysis from cervical infection to cancer. Int. J. Cancer 2012, 131, 2349-2359. [CrossRef] [PubMed]

17. De Sanjose, S.; Quint, W.G.; Alemany, L.; Geraets, D.T.; Klaustermeier, J.E.; Lloveras, B.; Tous, S.; Felix, A.; Bravo, L.E.; Shin, H.R.; et al. Human papillomavirus genotype attribution in invasive cervical cancer: A retrospective cross-sectional worldwide study. Lancet Oncol. 2010, 11, 1048-1056. [CrossRef]

18. Serrano, B.; de Sanjosé, S.; Tous, S.; Quiros, B.; Muñoz, N.; Bosch, X.; Alemany, L. Human papillomavirus genotype attribution for HPVs 6, 11, 16, 18, 31, 33, 45, 52 and 58 in female anogenital lesions. Eur. J. Cancer 2015, 51, 1732-1741. [CrossRef] [PubMed]

19. Taylor, S.; Bunge, E.; Bakker, M.; Castellsagué, X. The incidence, clearance and persistence of non-cervical human papillomavirus infections: A systematic review of the literature. BMC Infect. Dis. 2016, 16, 293. [CrossRef] [PubMed]

20. Ndiaye, C.; Mena, M.; Alemany, L.; Arbyn, M.; Castellsagué, X.; Laporte, L.; Bosch, F.X.; de Sanjosé, S.; Trottier, H. HPV DNA, E6/E7 mRNA, and p16INK4a detection in head and neck cancers: A systematic review and meta-analysis. Lancet Oncol. 2014, 15, 1319-1331. [CrossRef] 
21. Mirabello, L.; Yeager, M.; Cullen, M.; Boland, J.F.; Chen, Z.; Wentzensen, N.; Zhang, X.; Yu, K.; Yang, Q.; Mitchell, J.; et al. HPV16 Sublineage Associations with Histology-Specific Cancer Risk Using HPV Whole-Genome Sequences in 3200 Women. J. Natl. Cancer Inst. 2016, 108, djw100. [CrossRef] [PubMed]

22. Cornet, I.; Gheit, T.; Iannacone, M.R.; Vignat, J.; Sylla, B.S.; Del Mistro, A.; Franceschi, S.; Tommasino, M.; Clifford, G.M. HPV16 genetic variation and the development of cervical cancer worldwide. Br. J. Cancer 2013, 108, 240-244. [CrossRef] [PubMed]

23. Gheit, T.; Cornet, I.; Clifford, G.M.; Iftner, T.; Munk, C.; Tommasino, M.; Kjaer, S.K. Risks for persistence and progression by human papillomavirus type 16 variant lineages among a population-based sample of Danish women. Cancer Epidemiol. Biomark. Prev. 2011, 20, 1315-1321. [CrossRef] [PubMed]

24. Hildesheim, A.; Schiffman, M.; Bromley, C.; Wacholder, S.; Herrero, R.; Rodriguez, A.C.; Bratti, M.C.; Sherman, M.E.; Scarpidis, U.; Lin, Q.-Q.; et al. Human papillomavirus type 16 variants and risk of cervical cancer. J. Natl. Cancer Inst. 2001, 93, 315-318. [CrossRef] [PubMed]

25. Pientong, C.; Wongwarissara, P.; EkalaksanananEmail, T.; Swangphon, P.; Kleebkaow, P.; Kongyingyoes, B.; Siriaunkgul, S.; Tungsinmunkong, K.; Suthipintawong, C. Association of human papillomavirus type 16 long control region mutation and cervical cancer. Virol. J. 2013, 10, 30. [CrossRef] [PubMed]

26. Rabelo-Santos, S.H.; Villa, L.L.; Derchain, S.F.; Ferreira, S.; Sarian, L.O.; Angelo-Andrade, L.A.; do Amaral Westin, M.C.; Zeferino, L.C. Variants of human papillomavirus types 16 and 18: Histological findings in women referred for atypical glandular cells or adenocarcinoma in situ in cervical smear. Int. J. Gynecol. Pathol. 2006, 25, 393-397. [CrossRef] [PubMed]

27. Schiffman, M.; Rodriguez, A.C.; Chen, Z.; Wacholder, S.; Herrero, R.; Hildesheim, A.; Desalle, R.; Befano, B.; Yu, K.; Safaeian, M.; et al. A population-based prospective study of carcinogenic human papillomavirus variant lineages, viral persistence, and cervical neoplasia. Cancer Res. 2010, 70, 3159-3169. [CrossRef] [PubMed]

28. Xi, L.F.; Koutsky, L.A.; Hildesheim, A.; Galloway, D.A.; Wheeler, C.M.; Winer, R.L.; Ho, J.; Kiviat, N.B. Risk for high-grade cervical intraepithelial neoplasia associated with variants of human papillomavirus types 16 and 18. Cancer Epidemiol. Biomark. Prev. 2007, 16, 4-10. [CrossRef] [PubMed]

29. Zehbe, I.; Voglino, G.; Delius, H.; Wilander, E.; Tommasino, M. Risk of cervical cancer and geographical variations of human papillomavirus 16 E6 polymorphisms. Lancet 1998, 352, 1441-1442. [CrossRef]

30. Zuna, R.E.; Moore, W.E.; Shanesmith, R.P.; Dunn, S.T.; Wang, S.S.; Schiffman, M.; Blakey, G.L.; Teel, T. Association of HPV16 E6 variants with diagnostic severity in cervical cytology samples of 354 women in a US population. Int. J. Cancer 2009, 125, 2609-2613. [CrossRef] [PubMed]

31. Sichero, L.; Ferreira, S.; Trottier, H.; Duarte-Franco, E.; Ferenczy, A.; Franco, E.L.; Villa, L.L. High grade cervical lesions are caused preferentially by non-European variants of HPVs 16 and 18. International J. Cancer 2007, 120, 1763-1768. [CrossRef] [PubMed]

32. Berumen, J.; Ordoñez, R.M.; Lazcano, E.; Salmeron, J.; Galvan, S.C.; Estrada, R.A.; Yunes, E.; Garcia-Carranca, A.; Gonzalez-Lira, G.; Madrigal-de la Campa, A.; et al. Asian-American Variants of Human Papillomavirus 16 and Risk for Cervical Cancer: A Case-Control Study. J. Natl. Cancer Inst. 2001, 93, 1325-1330. [CrossRef] [PubMed]

33. Freitas, L.B.; Chen, Z.; Muqui, E.F.; Boldrini, N.A.T.; Miranda, A.E.; Spano, L.C.; Burk, R.D. Human Papillomavirus 16 Non-European Variants Are Preferentially Associated with High-Grade Cervical Lesions. PLoS ONE 2014, 9, e100746. [CrossRef] [PubMed]

34. Burk, R.D.; Terai, M.; Gravitt, P.E.; Brinton, L.A.; Kurman, R.J.; Barnes, W.A.; Greenberg, M.D.; Hadjimichael, O.C.; Fu, L.; McGowan, L.; et al. Distribution of Human Papillomavirus Types 16 and 18 Variants in Squamous Cell Carcinomas and Adenocarcinomas of the Cervix. Cancer Res. 2003, 63, 7215-7220. [PubMed]

35. Quint, K.D.; de Koning, M.N.; van Doorn, L.J.; Quint, W.G.; Pirog, E.C. HPV genotyping and HPV16 variant analysis in glandular and squamous neoplastic lesions of the uterine cervix. Gynecol. Oncol. 2010, 117, 297-301. [CrossRef] [PubMed]

36. Nicolás-Párraga, S.; Alemany, L.; de Sanjosé, S.; Bosch, F.X.; Bravo, I.G.; RIS HPV TT and HPV VVAP Study Groups. Differential HPV16 variant distribution in squamous cell carcinoma, adenocarcinoma and adenosquamous cell carcinoma. Int. J. Cancer 2017, 140, 2092-2100.

37. Mirabello, L.; Yeager, M.; Yu, K.; Clifford, G.M.; Xiao, Y.; Zhu, B.; Cullen, M.; Boland, J.F.; Wentzensen, N.; Nelson, C.W.; et al. HPV16 E7 genetic conservation is critical to carcinogenesis. Cell 2017, 170, 1164-1174. [CrossRef] [PubMed] 
38. Cullen, M.; Boland, J.F.; Schiffman, M.; Zhang, X.; Wenzensen, N.; Yang, Q.; Chen, Z.; Yu, K.; Mitchell, J.; Roberson, D.; et al. Deep sequencing of HPV16 genomes: A new high-throughput tool for exploring the carcinogenicity and natural history of HPV16 infection. Papillomavirus Res. 2015, 1, 3-11. [CrossRef] [PubMed]

39. Schiffman, M.; Kinney, W.K.; Cheung, L.C.; Gage, J.C.; Fetterman, B.; Poitras, N.E.; Lorey, T.S.; Wentzensen, N.; Befano, B.; Schussler, J.; et al. Relative Performance of HPV and Cytology Components of Cotesting in Cervical Screening. JNCI J. Natl. Cancer Inst. 2017. [CrossRef] [PubMed]

40. Bray, F.; Carstensen, B.; Møller, H.; Zappa, M.; Zakelj, M.P.; Lawrence, G.; Hakama, M.; Weiderpass, E. Incidence Trends of Adenocarcinoma of the Cervix in 13 European Countries. Cancer Epidemiol. Biomark. Prev. 2005, 14, 2191-2199. [CrossRef] [PubMed]

41. Gien, L.T.; Beauchemin, M.-C.; Thomas, G. Adenocarcinoma: A unique cervical cancer. Gynecol. Oncol. 2010, 116, 140-146. [CrossRef] [PubMed]

42. Di Bonito, L.; Bergeron, C. Cytological screening of endocervical adenocarcinoma. Ann. Pathol. 2012, 32, e8-e14. [CrossRef] [PubMed]

43. Davy, M.L.J.; Dodd, T.J.; Luke, C.G.; Roder, D.M. Cervical cancer: Effect of glandular cell type on prognosis, treatment, and survival. Obstet. Gynecol. 2003, 101, 38-45. [CrossRef] [PubMed]

44. Ault, K.A.; Joura, E.A.; Kjaer, S.K.; Iversen, O.E.; Wheeler, C.M.; Perez, G.; Brown, D.R.; Koutsky, L.A.; Garland, S.M.; Olsson, S.E.; et al. Adenocarcinoma in situ and associated human papillomavirus type distribution observed in two clinical trials of a quadrivalent human papillomavirus vaccine. Int. J. Cancer 2011, 128, 1344-1353. [CrossRef] [PubMed]

45. The Cancer Genome Atlas Research Network. Integrated genomic and molecular characterization of cervical cancer. Nature 2017, 543, 378-384.

46. Litwin, T.; Clarke, M.A.; Dean, M.; Wentzensen, N. Somatic Host Cell Alterations in HPV Carcinogenesis. Viruses 2017, 9, 206. [CrossRef] [PubMed]

47. Doorbar, J.; Quint, W.; Banks, L.; Bravo, I.G.; Stoler, M.; Broker, T.R.; Stanley, M.A. The biology and life-cycle of human papillomaviruses. Vaccine 2012, 30 (Suppl. 5), F55-F70. [CrossRef] [PubMed]

48. Herfs, M.; Yomamoto, Y.; Laury, A.; Wang, X.; Nucci, M.R.; McLaughlin-Drubin, M.E.; Münger, K.; Feldman, S.; McKeon, F.D.; Xian, W.; et al. A discrete population of squamocolumnar junction cells implicated in the pathogenesis of cervical cancer. Proc. Natl. Acad. Sci. USA 2012, 109, 10516-10521. [CrossRef] [PubMed]

49. Vande Pol, S.B.; Klingelhutz, A.J. Papillomavirus E6 oncoproteins. Virology 2013, 445, 115-137. [CrossRef] [PubMed]

50. Roman, A.; Munger, K. The papillomavirus E7 proteins. Virology 2013, 445, 138-168. [CrossRef] [PubMed]

51. Boon, S.S.; Banks, L. High-risk human papillomavirus E6 oncoproteins interact with 14-3-3zeta in a PDZ binding motif-dependent manner. J. Virol. 2013, 87, 1586-1595. [CrossRef] [PubMed]

52. Boon, S.S.; Tomaića, V.; Thomasa, M.; Robertsb, S.; Banksa, L. Cancer-causing human papillomavirus E6 proteins display major differences in the phospho-regulation of their PDZ interactions. J. Virol. 2015, 89, 1579-1586. [CrossRef] [PubMed]

53. Egawa, N.; Egawa, K.; Griffin, H.; Doorbar, J. Human Papillomaviruses; Epithelial Tropisms, and the Development of Neoplasia. Viruses 2015, 7, 3863-3890. [CrossRef] [PubMed]

54. Kranjec, C.; Doorbar, J. Human papillomavirus infection and induction of neoplasia: A matter of fitness. Curr. Opin. Virol. 2016, 20, 129-136. [CrossRef] [PubMed]

55. Palmer, E.; Newcombe, R.G.; Green, A.C.; Kelly, C.; Noel Gill, O.; Hall, G.; Fiander, A.N.; Pirotte, E.; Hibbitts, S.J.; Homer, J.; et al. Human papillomavirus infection is rare in nonmalignant tonsil tissue in the UK: Implications for tonsil cancer precursor lesions. Int. J. Cancer 2014, 135, 2437-2443. [CrossRef] [PubMed]

56. Schiffman, M.; Wentzensen, N. Human papillomavirus infection and the multistage carcinogenesis of cervical cancer. Cancer Epidemiol. Biomark. Prev. 2013, 22, 553-560. [CrossRef] [PubMed]

57. Schwartz, S. Papillomavirus transcripts and posttranscriptional regulation. Virology 2013, 445, 187-196. [CrossRef] [PubMed]

58. Johansson, C.; Schwartz, S. Regulation of human papillomavirus gene expression by splicing and polyadenylation. Nat. Rev. Microbiol. 2013, 11, 239-251. [CrossRef] [PubMed]

59. Kajitani, N.; Schwartz, S. RNA Binding Proteins that Control Human Papillomavirus Gene Expression. Biomolecules 2015, 5, 758-774. [CrossRef] [PubMed] 
60. Straub, E.; Dreer, M.; Fertey, J.; Iftner, T.; Stubenrauch, F. The viral E8^E2C repressor limits productive replication of human papillomavirus 16. J. Virol. 2014, 88, 937-947. [CrossRef] [PubMed]

61. Vinokurova, S.; Wentzensen, N.; Kraus, I.; Klaes, R.; Driesch, C.; Melsheimer, P.; Kisseljov, F.; Dürst, M.; Schneider, A.; von Knebel Doeberitz, M.; et al. Type-dependent integration frequency of human papillomavirus genomes in cervical lesions. Cancer Res. 2008, 68, 307-313. [CrossRef] [PubMed]

62. Wentzensen, N.; Ridder, R.; Klaes, R.; Vinokurova, S.; Schaefer, U.; von Knebel Doeberitz, M. Characterization of viral-cellular fusion transcripts in a large series of HPV16 and 18 positive anogenital lesions. Oncogene 2002, 21, 419-426. [CrossRef] [PubMed]

63. Akagi, K.; Li, J.; Broutian, T.R.; Padilla-Nash, H.; Xiao, W.; Jiang, B.; Rocco, J.W.; Teknos, T.N.; Kumar, B.; Wangsa, D.; et al. Genome-wide analysis of HPV integration in human cancers reveals recurrent, focal genomic instability. Genome Res. 2014, 24, 185-199. [CrossRef] [PubMed]

64. Wentzensen, N.; Vinokurova, S.; von Knebel Doeberitz, M. Systematic Review of Genomic Integration Sites of Human Papillomavirus Genomes in Epithelial Dysplasia and Invasive Cancer of the Female Lower Genital Tract. Cancer Res. 2004, 64, 3878-3884. [CrossRef] [PubMed]

65. Bodelon, C.; Vinokurova, S.; Sampson, J.N.; den Boon, J.A.; Walker, J.L.; Horswill, M.A.; Korthauer, K.; Schiffman, M.; Sherman, M.E.; Zuna, R.E.; et al. Chromosomal copy number alterations and HPV integration in cervical precancer and invasive cancer. Carcinogenesis 2016, 37, 188-196. [CrossRef] [PubMed]

66. Hu, Z.; Zhu, D.; Wang, W.; Li, W.; Jia, W.; Zeng, X.; Ding, W.; Yu, L.; Wang, X.; Wang, L.; et al. Genome-wide profiling of HPV integration in cervical cancer identifies clustered genomic hot spots and a potential microhomology-mediated integration mechanism. Nat Genet. 2015, 47, 158-163. [CrossRef] [PubMed]

67. Schmitz, M.; Driesch, C.; Jansen, L.; Runnebaum, I.B.; Dürst, M. Non-random integration of the HPV genome in cervical cancer. PLoS ONE 2012, 7, e39632. [CrossRef] [PubMed]

68. El Awady, M.K.; Kaplan, J.B.; O’Brien, S.J.; Burk, R.D. Molecular analysis of integrated human papillomavirus 16 sequences in the cervical cancer cell line SiHa. Virology 1987, 159, 389-398. [CrossRef]

69. Bodelon, C.; Untereiner, M.E.; Machiela, M.J.; Vinokurova, S.; Wentzensen, N. Genomic characterization of viral integration sites in HPV-related cancers. Int. J. Cancer 2016, 139, 2001-2011. [CrossRef] [PubMed]

70. Couturier, J.; Sastre-Garau, X.; Schneider-Maunoury, S.; Labib, A.; Orth, G. Integration of papillomavirus DNA near myc genes in genital carcinomas and its consequences for proto-oncogene expression. J. Virol. 1991, 65, 4534-4538. [PubMed]

71. Jackson, R.; Rosa, B.A.; Lameiras, S.; Cuninghame, S.; Bernard, J.; Floriano, W.B.; Lambert, P.F.; Nicolas, A.; Zehbe, I. Functional variants of human papillomavirus type 16 demonstrate host genome integration and transcriptional alterations corresponding to their unique cancer epidemiology. BMC Genom. 2016, $17,851$. [CrossRef] [PubMed]

72. De Jong, A.; van Poelgeest, M.I.; van der Hulst, J.M.; Drijfhout, J.W.; Fleuren, G.J.; Melief, C.J.; Kenter, G.; Offringa, R.; van der Burg, S.H. Human Papillomavirus Type 16-Positive Cervical Cancer Is Associated with Impaired CD4+ T-Cell Immunity against Early Antigens E2 and E6. Cancer Res. 2004, 64, 5449-5455. [CrossRef] [PubMed]

73. Chen, Z.; Terai, M.; Fu, L.; Herrero, R.; DeSalle, R.; Burk, R.D. Diversifying Selection in Human Papillomavirus Type 16 Lineages Based on Complete Genome Analyses. J. Virol. 2005, 79, 7014-7023. [CrossRef] [PubMed]

74. Roura, E.; Castellsagué, X.; Pawlita, M.; Travier, N.; Waterboer, T.; Margall, N.; Bosch, F.X.; de Sanjosé, S.; Dillner, J.; Gram, I.T.; et al. Smoking as a major risk factor for cervical cancer and pre-cancer: Results from the EPIC cohort. Int. J. Cancer 2014, 135, 453-466. [CrossRef] [PubMed]

75. Chen, D.; Juko-Pecirep, I.; Hammer, J.; Ivansson, E.; Enroth, S.; Gustavsson, I.; Feuk, L.; Magnusson, P.K.; McKay, J.D.; Wilander, E.; et al. Genome-wide Association Study of Susceptibility Loci for Cervical Cancer. J. Natl. Cancer Inst. 2013, 105, 624-633. [CrossRef] [PubMed]

76. Shi, Y.; Li, L.; Hu, Z.; Li, S.; Wang, S.; Liu, J.; Wu, C.; He, L.; Zhou, J.; Li, Z.; et al. A genome-wide association study identifies two new cervical cancer susceptibility loci at 4q12 and 17q12. Nat Genet. 2013, 45, 918-922. [CrossRef] [PubMed]

77. Ivansson, E.L.; Juko-Pecirep, I.; Erlich, H.A.; Gyllensten, U.B. Pathway-based analysis of genetic susceptibility to cervical cancer in situ: HLA-DPB1 affects risk in Swedish women. Genes Immun. 2011, 12, 605-614. [CrossRef] [PubMed] 
78. Zehbe, I.; Mytilineos, J.; Wikström, I.; Henriksen, R.; Edler, L.; Tommasino, M. Association between human papillomavirus $16 \mathrm{E} 6$ variants and human leukocyte antigen class I polymorphism in cervical cancer of Swedish women. Hum. Immunol. 2003, 64, 538-542. [CrossRef]

79. Zehbe, I.; Tachezy, R.; Mytilineos, J.; Voglino, G.; Mikyskova, I.; Delius, H.; Marongiu, A.; Gissmann, L.; Wilander, E.; Tommasino, M. Human papillomavirus 16 E6 polymorphisms in cervical lesions from different European populations and their correlation with human leukocyte antigen class II haplotypes. Int. J. Cancer 2001, 94, 711-716. [CrossRef] [PubMed]

(C) 2018 by the authors. Licensee MDPI, Basel, Switzerland. This article is an open access article distributed under the terms and conditions of the Creative Commons Attribution (CC BY) license (http:/ / creativecommons.org/licenses/by/4.0/). 